\title{
Arbor
}

\section{San Millán de la Cogolla. Ida y Vuelta de Diez Siglos de Castellano}

\author{
Ángel Martín Municio
}

Arbor CLXXIX, 706 (Octubre 2004), 513-524 pp.

Es del todo obvio que las cosas, cada cosa, no son sino valores. No hay una realidad única e invariable. De forma que, al acercarnos a cada una de ellas con distintas apreciaciones, obtendremos, en lugar de una sola cosa, una colección de cosas diferentes. Para un labriego tradicional, la tierra era simplemente, hasta no hace mucho tiempo, una siembra, unos surcos y una mies; le preocupaban los abonos, y las lluvias; y soñaba con la cosechadora mecánica. Al cabo de no demasiados años, se cuida hoy de sacar a la tierra varias cosechas con semillas transgénicas y un clima a la medida. Para un astrónomo, la Tierra, además de exigir el tratamiento de "mayúscula», es un planeta del sistema solar; le preocupan la interpretación matemática de la gravitación universal y el origen de los neutrinos; y sueña con la unificación de las fuerzas del universo.

A la lengua podemos acercarnos, pues, desde múltiples sistemas de valoración. La lengua tiene tantas realidades como numerosos puntos de examen, de cuyo conjunto nace un formidable panorama en el que sobresale la vinculación del lenguaje con la misma naturaleza humana. Y, dentro de este panorama, el estudio de la lengua puede abarcar en la actualidad desde el etimologismo purista de sus orígenes clásicos hasta las aplicaciones matemáticas del cálculo de probabilidades o de la «teoría de la decisión» a la desambiguación lingüística en la construcción y uso de los grandes corpus. Algunas de esas realidades son vagas, laxas, cuyas aproximaciones bastan para los usos del vivir cotidiano. Hay, además, otras realidades forjadas en un sistema de relaciones más exactas, científicas. Y, en su derredor, mitos, religiones y filosofías, que, durante mu- 
chos siglos, sustentan lógicas o peregrinas ideas sobre los orígenes del lenguaje. Origen que si bien tropieza con insuperables dificultades en su identificación naturalista, tiene muy claro que no puede separarse de la consideración de la naturaleza humana y de la sociedad humana. Y también que la adquisición de la aptitud anatomofisiológica del hombre para el habla hubo de coordinarse con la evolución de sus capacidad cerebral para la modulación del pensamiento y expresar lo que piensa o siente. Y este pensamiento central del hombre primitivo sería su idea de Dios, del universo, de la cantidad y calidad de sus relaciones. Por ello, no tiene demasiada importancia si las primeras señales de una incipiente comunicación científica fueron los elementales algoritmos de las tablillas de arcilla en el periodo paleobabilónico, o los cálculos de volúmenes en los papiros egipcios del segundo milenio antes de nuestra era, o el sistema sexagesimal mesopotámico. Da igual porque la comunicación matemática nació cuando, cientos de miles de años antes, las conexiones sinápticas del cerebro en evolución permitieron al hombre contar, en coincidencia con el origen del lenguaje y en coincidencia con el origen de su propia naturaleza; para, luego, en su interacción con el pensamiento, comenzar el razonamiento abstracto. Y no será en vano que filósofos, lingüistas y antropólogos, coincidan en reconocer que sin el concurso de los signos seríamos incapaces de reconocer las ideas. El pensamiento en sí mismo sería como una nebulosa donde nada está necesariamente delimitado, y donde nada sería distinto antes de la aparición de la lengua. De aquí que el pensamiento sea imposible sin lenguaje; y más aún, como aseguró en el s. XVIII el gran naturalista Buffon, el hombre habla debido a que tiene razón. Y es que todo hombre piensa en su lengua, y ella se identifica con sus imaginaciones y sentimientos.

De esta manera, el lenguaje sirvió siempre para expresar las preocupaciones del pensamiento acerca del origen y la naturaleza del hombre y del universo. Y expresión de estas preocupaciones habrían de ser las creaciones literarias mítico-religiosas en todas las lenguas; las que darían paso a la exaltación artística de los mitos y, a su lado, al razonamiento filosófico y al razonamiento matemático.

Y no deja de ser impresionante que hoy, al cabo de tantos años, la moderna imagen funcional del cerebro -y que, a no dudarlo, su tecnología ha nacido a expensas de la matemática moderna- sea capaz de mostrar una localización cerebral del ejercicio matemático, diferente de la localización responsable del lenguaje. Si esta habilidad matemática, consustancial por otro lado al ejercicio de la ciencia, fue, pues, independiente a la vez que pareja al lenguaje -competencias ambas intrínsecas del hom- 
bre- no tendrá nada de extraño que la marcha de ambos haya caminado en paralelo. Y que una de las particularidades más significativas de la expresión del pensamiento del hombre, con sus altibajos y sus renovaciones, haya sido siempre la preocupación científica por su propia naturaleza y la de su presencia en el universo.

Hasta que, tras un enorme salto, nos encontramos hoy con las numerosas perspectivas de su estudio tanto de la ciencia lingüística como de la historia de los lenguajes y su uso en la creación filosófica, científica y literaria. Lo que ha conducido a la moderna ciencia del lenguaje que incorpora al estudio de las lenguas particulares toda una serie de aportaciones convergentes por parte de la filosofía, de las ciencias biológicas, sociales y del comportamiento. No en balde, la palabra -en texto de Emilio Lledó- es, para la existencia, el alimento de su maduración y el inagotable caudal de su libertad para pensar. No hay otra posibilidad de crecer interiormente sino en el universo especulativo del lenguaje ante cuya visión nos encontramos y nos reconocemos(...)Pero la palabra no sólo transmite la memoria $y$, por consiguiente, la memoria del pasado sino que, desde ella, se puede organizar el porvenir. Al ser el lenguaje la aportación definidora del ser humano, su cultivo y crítica nutre el principio sobre el que se funda también el desarrollo individual y, en consecuencia, su posible futuro.

Moderna ciencia del lenguaje que, en la actualidad, en uno de los cambios sociales mas acusados en la historia de la civilización, es sustrato de los tratamientos tecnológicos que aplican la informática, la estadística, la microelectrónica y las nuevas comunicaciones para dar lugar, por ejemplo, a la traducción automática, al reconocimiento de voz, a la construcción y consulta de los grandes corpus lingüísticos y a la transmisión instantánea de la información.

Creo que todo ello tiene mucho que ver con cualquier recuerdo $\mathbf{y}$ cualquier evocación de las más variadas coordenadas de la lengua, de su geografía y de su historia, en el espacio y en el tiempo. Tiene que ver, pues, y sobre todo, con la infinitud hispanoamericana. Porque la lengua fue, y su camino natural nos lo recuerda y advierte, la materia y el espíritu que abrieron paso al famoso lema de los Reyes Católicos: leer, escribir y rezar.

Efectivamente, los balbuceos romances de la lengua castellana -a los vagidos se referirían Menéndez Pidal, Dámaso Alonso y Emilio Alarcostuvieron sus testimonios más antiguos en los escritos de los cenobios riojanos, sin que pueda delimitarse con precisión geográfica e histórica las 
distancias entre la tradición latina documental y las lenguas coloquiales, de un lado, y los incipientes rasgos literarios de los pergaminos, de otro.

Si esta confluencia entre lenguas, ante la carencia de fuentes orales principalmente, no puede llegar a establecerse con precisión, no resultarán extrañas las grandes dificultades con que tropiezan la investigación y las especulaciones biológicas acerca del origen del lenguaje. Porque ver y tocar las cosas -como dijera el filósofo- no son, al cabo, sino maneras de pensarlas. Y el pensamiento central del hombre primitivo no fue la aritmética ni la física, fue su idea de Dios, del universo y de sus relaciones. O lo que es igual, el lenguaje no fue, y no lo es, único instrumento de comunicación humana, sino también intercambio de abstracciones mentales para las conversaciones más importantes, las conversaciones consigo mismo y con Dios.

Solamente así se explica la porfía incesante del primer capítulo del Génesis: "Dijo Dios»; dijo Dios con su palabra interna, en su decisión, por su pensamiento. Y la rotunda influencia lingüística del capítulo segundo, cuando, tras haber sido creadas todas las bestias de la Tierra las llevó a Adán, "Y Yavé Dios trajo ante el hombre todos cuantos animales del campo y cuantas aves del cielo formó de la tierra, para que viese como los llamaría, y fuese el nombre de todos los vivientes el que él les diera. Y dio el hombre nombre a todos los ganados y a todas las aves del cielo, y a todas las bestias del campon.

Sólo así cabe pensar en las conversaciones consigo mismo de aquellas soledades buscadoras de trascendencia de los eremitas cristianos de los primeros siglos, dedicados al estudio y al ejercicio de las virtudes, que poblaron las covachas de los montículos de Nájera, y que anticiparon a las pequeñas comunidades de anacoretas y a la misma vida monástica comunitaria. Aquellas fábricas de soledad -que llamara Ortega- las de tantos cenobios en la cima de un monte, con un ciprés y una espadaña para amansar las pasiones de unos cuantos sayales con el color de la tierra, pulidas sus almas como cantos rodados. Y, de esta manera, por los montes Distercios, milagreaba San Millán, en los s. V y VI, en la transición de la soledad liberadora a los rediles cenobíticos. San Millán, nacido en torno al año 473, cantado por el obispo Braulio de Zaragoza y paradigma del monaquismo hispano mediado el s. VII; gracias sobre todo al entrañable recuerdo que le dedicara el primer gran poeta castellano Gonzalo de Berceo, resaltando en él la ciencia y las creencias: 
San Millán de la Cogolla. Ida y Vuelta de Diez Siglos...

Quanto en la çiencia era más embevido,

Tanto en la creençia era más ençendido;

Ya querría del castiello fuera ser exido,

Por tornar a los montes, bevir más escondido.

$\mathrm{Y}$ de pronto, la vida monástica, sin abandonar su originario apartamiento del mundo, comenzaba a integrarse en él; los monjes, a la vez que continuaban en la humildad y la obediencia, cambiarían los métodos y los fines del monacato; los monasterios, recintos de oración y ascetismo, ampliarán sus funciones, albergarán tesoros materiales y espirituales, y en la actividad de los monjes participará la lectura, la creación de bibliotecas, la copia de manuscritos y, en general, la actividad intelectual. Porque, además, en el carácter arcaico de aquella sociedad castellana, la organización eclesiástica se incrustaba en la incipiente organización socio-económica.

Sólo así se entiende la definición de la experiencia mística que, en "Llama de amor viva", hiciera declarar a San Juan de la Cruz que "el lenguaje propio de cosas tan subidas es entenderlo para sí y sentirlo y gozarlo y callarlo el que lo tienen. Sólo así se interpreta la referencia de Unamuno: "la lengua española pensó y sintió a Dios en Santa Teresa».

Y es así que todo hombre piensa en su lengua, y ella se identifica con sus imaginaciones y sentimientos; a través de ella habla consigo mismo, como nos lo cantara Unamuno:

La sangre de mi espíritu es mi lengua

$Y$ mi sangre es allí donde resuene

Soberano su verbo, que no amengua

Su voz, por mucho que ambos mundos lleve.

No tendrá entonces nada de extraño que a esta manifestación superior de racionalidad se refiriese el filólogo hispanoamericano Amado Alonso, a propósito de cuantos hablan una lengua: "No es la lengua un organismo vegetal, ni animal, ni natural, ni tiene leyes autónomas, ni condiciones de existencia ajenas a la intervención de los hablantes; ha sido lo que sus hablantes hicieron de ella, es lo que están haciendo y será lo que hagan de ella. Nuestra lengua y su porvenir está en nuestras manos, en nuestra voluntad, en nuestra intervención cotidiana y activan.

$\mathrm{Y}$ así, ya en el siglo X, bajo el gobierno del abad Gomesano, el scriptorium de San Millán, centro neurálgico de la biblioteca, pudo participar en el porvenir de la lengua neonata con los Comentarios a los Salmos, la copia de la Ciudad de Dios de San Agustín, y, sobre todo, el famoso códi- 
ce 46, diccionario enciclopédico de la época con el vocabulario, la cultura y el pensamiento medievales; que fuera el más antiguo precursor del famoso "Diccionario de Autoridades», la primera edición, hace más de dos siglos, de la obra que llega a su vigésima segunda edición en los comienzos del siglo XXI.

Diez siglos isí! de ida y vuelta. Al concluir el siglo XX, San Millán vuelve a ser centro neurálgico de la lengua castellana al recibir, al cabo de diez siglos, su premio como patrimonio de la humanidad. Por lo uno y por lo otro, y en fe de todo ello, acuden a San Millán y se reúnen en su Monasterio todas las Academias de la Lengua Española. Son veintidós Academias las que ahora vuelven a San Millán; y con ellas, jirones de nuestra historia, fruto y semilla a la vez de aquella lengua castellana, convertida en española.

A partir de entonces, en el avance de los siglos medievales se consolidan los territorios de la corona de Castilla; aumentan los núcleos de población; el fortalecimiento de la vida urbana origina la aparición de las voces burgo, vico, suburbio y barrio; tiene lugar el aposentamiento estable de la artesanía a la vez que algunas de sus manifestaciones, la textil por ejemplo, adquieren mayor peso económico y social; aparecen las primeras ferias; se generalizan las concesiones de fueros y se complica la estructura social. Situación social, económica y política, que, indudablemente, se interpenetró con el marco de la actividad y el poder de los patrimonios monásticos, y a cuyo conjunto no tuvo que ser ajena la crisis de la sociedad feudal en la alta Edad Media. Monasterios los de San Millán de la Cogolla, Santo Domingo de Silos, Oña, Cardeña, San Pedro de Arlanza, San Miguel de Escalada, San Pedro de Lara, Santa María de Bujedo, San Juan de Burgos, San Zoilo de Carrión, San Facundo en Sahagún, San Martín de Castañeda, Santa Maria de Obarenes, y, entre los últimos medievales, las Cartujas de El Paular en Segovia, Aniago en Valladolid y Miraflores en Burgos. Y muchos otros, algunos aún en la realidad presente y otros solamente en el recuerdo; todos ellos núcleos de la tradición eclesiástica y de encuentro con la trascendencia espiritual, y, siempre, mojones de este camino de la lengua, metáfora y realidad de aquel Camino de Santiago que se cuenta recorriera peregrino en 1213 el mismísimo Francisco de Asís, comienzo de los asentamientos franciscanos en los reinos peninsulares.

Ante aquellos iniciales documentos, ante las innovaciones y las vacilaciones lingüísticas de hace un milenio, no tenemos sino que reconocer con Marañón los esfuerzos de los que nos precedieron en los siglos 
San Millán de la Cogolla. Ida y Vuelta de Diez Siglos...

pasados, porque los que heredan una gran riqueza no se dan cuenta de ella como los que han tenido que ganarla con su esfuerzo. Nosotros tenemos situación de privilegio por haber aprendido esta lengua clara de Castilla. Pero este privilegio lo tenemos que merecer cada día con nuestro esfuerzo y con nuestro amor. El tesoro de una lengua ilustre significa un servicio permanentemente alerta, un anhelo constante de perfección. Lo han merecido, en efecto, todos los que, tras los balbuceos monacales, han ido pasando hasta nuestros días el testigo de la perfección y la belleza de la lengua, de un lado, y, de otro, los que en empresas militares, misioneras, y colonizadoras, la aventaron por mares y continentes. El testigo que, a modo de romance, acompañó al Cid en sus correrías militares; que ya como lengua de la ciencia y la tecnología sirvió a Alfonso X en el «Saber de Astronomían; que fue usada para legislar por Don Sancho Ramirez Rey de Aragón; que se convirtió en dejes de melancolía en las coplas de Jorge Manrique; que fue picardía popular en los versos del Arcipreste y poesía regia en las obras de los Reyes de Aragón Pedro II y Pedro III; y que se convirtió en oración real en palabras de Santa Isabel, Infanta de Aragón y Reina de Portugal. Lengua que se hizo norma en la gramática de Nebrija, poesía en Garcilaso, novela en el Lazarillo, comedia en la Celestina, espiritualidad enardecida en San Juan de la Cruz, perfección en Fray Luis, universalidad en Lope, y, en Cervantes, el arranque de los tiempos modernos en la historia del hombre. Lengua que, con Calderón, se hizo teología popular y con el Cronista Lupercio Leonardo de Argensola se utilizó para las grandes noticias de la Historia. Sirvió para la exaltación barroca de Góngora. En Quevedo, encontró el cincel para la burla y la ironía; en Baltasar Gracián, la permanente atención a la profundidad del pensamiento; en Jovellanos, el cuidado y el sentido estético de su prosa, aún cuando tratara de ramplones asuntos administrativos; y en el Padre Feijoo el análisis crítico de la evolución cultural española.

Tras el Descubrimiento y durante estos tres últimos siglos, los monarcas españoles, desde Carlos V y Felipe II a los primeros Borbones, pusieron un gran empeño en la tarea de difusión del castellano. Así, en una cédula del rey Felipe IV dirigida al arzobispo de Bogotá, en 1634, se dice: "Como sabéis, me tienen con particular cuidado y desvelo la crianza, educación y buen tratamiento de estos indios, por lo que deseo su alivio y bien de sus almas. Y aunque por diferentes células tengo encargado a mis Virreyes y Prelados, que las Iglesias de esta tierra velen sobre el cumplimiento de este intento, que se consiga, deseo todavía, considerando lo mucho que importa y las consecuencias que se seguirán a estos naturales sabiendo la lengua española, particularmente para ser enseñados con per- 
fección en nuestra Santa Fe Católica..., me ha parecido que a todos los naturales que estuvieren en la edad de su puericia y pudieren aprender la lengua castellana, se les enseñe...porque si no veláseis en ello y obligáseis a los otros doctrineros y demás súbditos vuestros a que hagan lo mismo, faltaréis a vuestra obligación con mucho riesgo de vuestra conciencia, que en esta parte os encargo, descargando la mía...."

Lengua que se hizo universal con las Crónicas de Indias de los protagonistas descubridores Cristóbal Colón, Hernán Cortés, Bernal Díaz del Castillo, Pedro de Valdivia, Alvar Núñez Cabeza de Vaca, Gonzalo Jiménez de Quesada y Pedro Cieza de León. Y que tuvo en el Inca Garcilaso no solo un espléndido ejemplo de transducción lingüística y cultural sino el origen de la prodigiosa dimensión de la literatura americana hecha realidad y fantasía, lógica y magia, capacidad narrativa y riqueza lingüística. Dimensión en la que, desde "La Florida del Inca" y los "Comentarios Reales" del hijo del capitán Garcilaso de la Vega, se ha visto fructificada en la novela contemporánea, como si esta común mitad de diez siglos de lengua compartida obedeciera desde sus inicios la orden poética de Dámaso Alonso:

Hermanos, los que estáis en lejanía

Tras las aguas inmensas, los cercanos

De mi España natal, todos hermanos

Porque habláis esta lengua que es la mía:

Yo digo "amor", yo digo "madre mía",

$Y$ atravesando mares, sierras, llanos,

-oh gozo-con sonidos castellanos,

os llega un dulce efluvio de poesía.

Yo exclamo "amigo", y en el Nuevo Mundo, "amigo" dice el eco, desde donde

cruza todo el Pacífico, y aún suena.

Yo digo "Dios", y hay un clamor profundo;

$Y$ "Dios", en español, todo responde,

$Y$ "Dios", sólo "Dios", "Dios", el mundo llena.

Y, a la vez, como si presintiera el pensamiento de Carlos Fuentes, en aquel párrafo de "El espejo enterrado": "La intérprete pero también la amante, la mujer de Cortés, La Malinche, estableció el hecho central de nuestra civilización, mezclando el sexo con el lenguaje. Ella fue la madre del hijo del conquistador, simbólicamente el primer mestizo. Madre del 
primer mexicano, del primer niño de sangre española e indígena. Y La Malinche parió hablando esta nueva lengua que aprendió de Cortés, la lengua española, lengua de la rebelión y la esperanza, de la vida y de la muerte, que habría de convertirse en liga más fuerte entre los descendientes de indios, europeos y negros en el hemisferio americano".

Efectivamente, la literatura colonial, a pesar de las distancias y los mares, se impregnó, en el siglo XVI, de la imaginación renacentista en "La Araucana", y tuvo en Sor Juana Inés de la Cruz, en el siglo XVII, la gran representante de la lírica barroca americana.

Las impresionantes aventuras del conocimiento, que significaron tanto las grandes expediciones del XVIII como las misiones científicas más reducidas en los campos más importantes de la botánica, la minería y la metalurgia, sacaron a relucir nombres ilustres -Alonso Barba, José Celestino Mutis, los hermanos Fausto y Juan José Elhuyar- que pusieron en marcha, durante muchos años, numerosas iniciativas sociales, científicas y del pensamiento, universidades incluidas, bajo el amparo de la lengua. Iniciativas, experiencia y entusiasmo sin límites de las gentes de la ciencia, que afianzaron la personalidad cultural de los reinos americanos. Sería injusto que en este momento pasáramos por alto a los tres únicos descubridores españoles de elementos químicos: Andrés Manuel del Río, licenciado por Alcalá, profesor de química del Real Seminario de Minería de México, descubridor en aquellas tierras del eritronio, el elemento 23 del sistema periódico, posteriormente conocido como vanadio; y, a su lado, los hermanos Elhuyar descubridores del wolframio, y el marino Ulloa descubridor del platino; y que, como en ninguna otra época, acercaron a Europa la naciente ciencia española.

Ocurría, además, y sigue ocurriendo, que las regiones periféricas, y este rincón del imperio lo era, y este camino de la lengua a su manera lo es también, tienen un singular metabolismo cultural. Ocurría y ocurre que la distancia de los centros neurálgicos de renovación cultural hace que sus propios productos sean recibidos con el retraso suficiente para que se ofrezcan distintos y, con apariencia de estatismo, se conserven más tardíamente. Y es allí mismo -asegura Maraval-, en esas regiones periféricas, en las que lo que se recibe de dentro con retraso se combina con lo que viene de fuera vez como novedad adelantada, son el lugar en que se produce de ese modo una primera síntesis de lo viejo y lo nuevo, de lo propio y lo ajeno, según un ritmo muy característico de retraso y anticipación. Pues, conforme a estas ideas, con toda seguridad fue Mutis uno de los representantes periféricos más fieles a esa especie de mosai- 
cismo cultural, a ese cambio de actitud mental, social y científica del hombre renacentista, cuando contempla la nueva relación del hombre consigo mismo y con el mundo, sus nuevas tierras, sus nuevos mares y su nueva naturaleza. Porque renacentista fue la atención tan singularizada que Mutis prestó a la experiencia y a la producción de libros sobre plantas. Pero, a la vez, sintió Mutis la necesidad ilustrada de una nueva organización para responder a las apetencias del conocimiento racional, del dominio de la naturaleza y de las causas de las cosas. Y bien merece la pena que anotemos la cita de Guillermo Hernández de Alba, presidente de la Academia de la Historia de Colombia, al reseñar la visita a Mutis de Humboldt y Bonpland: "Por dos meses comparten la mesa y el hogar del patriarca de los botánicos del Nuevo Mundo, que los desconcierta con su sabiduría increíble. Jamás soñaron los dos europeos encontrar en la lejana planicie bogotana una biblioteca especializada como en la misma Europa no llegaron a conocer. Ellos, tan difíciles de sorprender en cuestiones científicas, se vieron súbitamente en un paraíso sin sierpes engañosas de que era soberano un anciano sacerdote que hacía cuarenta años ilustraba las ciencias en tales términos que sería pasmo de las edades". La Borbonia augusta, uno de los más bonitos ejemplares de la Flora de Bogotá, dedicada por Mutis a Carlos III, fue a modo de delicado testamento del hombre sabio que amaba el conocimiento del mundo y deseó -en sus propias palabras- mostrar a la culta Europa lo que es, lo que vale, lo que importa este rincón del imperio.

Más tarde, si el romanticismo europeo obedeció a un proceso histórico, amplio y complejo, el romanticismo americano fue una expresión de las exigencias del patriciado criollo emergente de las luchas por la independencia, al estilo del "Martín Fierro" de José Hernández, una de las obras más famosas de la literatura argentina del XIX, y, sin duda, la maestra de la poesía gauchesca. Se imprimió la primera edición en papel de envolver, se vendió por pocos centavos en ranchos y pulperías, y la lengua de Castilla se leyó en voz alta en todas las tabernas de la pampa.

$\mathrm{Si}$, en efecto, la unidad de nuestra lengua tras la desunión política del XIX corrió gran riesgo, la presencia común de la Academia Española, por un lado, y, por otro, la aceptación por el castellano americano de sensibilidades independientes, con una renovación del lenguaje poético, un nuevo ritmo y una nueva estética, lograron sortear los posibles escollos. Quiere esto decir que el modernismo literario hispanoamericano, como nueva sensibilidad representada a finales de siglo por Rubén Dario y su obra en prosa y verso "Azul», significó no solo un gran momento de la literatura americana llena de optimismo y de elegancia verbal, sino la pre- 
sencia de nuevos intentos de renovación artística, y, a la vez, de nuevos escenarios de la lengua española con que compartir su unidad. De este movimiento se ha dicho: "Vocablos y giros, ritmos y figuras renovaron el instrumento. La prosa escogió sus epítetos, buscó efectos de visualidad $y$ sonoridad, adoptó la paciente taracea, aprendió la pincelada corta, nerviosa y segura de los impresionistas. El verso se hizo más flexible; los acentos cambiantes lo mostraron una rama dócil bajo la inquietud saltarina del pájaro. Metros arcaicos, elásticas yuxtaposiciones de pies distintos, ensayos de versolibrismo y de melodía interior, dejaron provechosa enseñanza. Pero en prosa y en verso el ornamento lujoso privó generalmente sobre la sustancia, y la opulencia externa tuvo así el esplendor momentáneo del follaje otoñal. El decenio siguiente barrió la hojarasca, salvó el fruto, cosechó la rica experiencian.

A la vez y solapante con el modernismo, una especie de realismo naturalista penetró ampliamente en el siglo XX siguiendo los pasos de variadas corrientes literarias europeas. A ello se refería el poeta venezolano Miguel Angel Pardo cuando comentaba de sí mismo: "Si en vez de conferenciante fuera yo novelista, sería como Balzac, cruel con la sociedad de la época; como Flaubert, sereno con las costumbres de la época; como Tolstoi, pesimista y despiadado con las arbitrariedades de la época; como Zola, censor viril y en cierto modo sublime transformador gigante de su épocan. Aludía con ello a la pretensión de este realismo de reflejar en el individuo los vicios de la sociedad y de sus instituciones. Los ensayos del mejicano Alfonso Reyes y del dominicano Pedro Henríquez Ureña, engarzan su estilo claro y brillante con la elegante prosa del Siglo de Oro español. En el ensayo "La utopía de América", Henriquez Ureña decía: "...en el mundo de la utopía no deberán desaparecer las diferencias de carácter que nacen del clima, de la lengua, de las tradiciones; pero todas estas diferencias, en vez de significar división y discordancia, deberán combinarse como matices diversos de la unidad humana....esperamos que cada región de América conserve y perfeccione todas sus actividades de carácter original, sobre todo en las artes: las literarias, en que nuestra originalidad se afirma cada dí; las plásticas, tanto las mayores como las menores, en que poseemos el doble tesoro, de la tradición española y de la tradición indígena, fundidas ya en corrientes nuevas...".

$\mathrm{Al}$ cabo de un siglo de independencia política, la literatura americana consolida su propia tradición. Y en expresión de Octavio Paz, ahora sabemos a ciencia cierta que somos contemporáneos de todos los hombres $y$ sabemos que formamos parte de una tradición cultural común...". Y para 
dar cumplida fe de ello, valga tan sólo una corta e incompleta sarta de grandes nombres: el peruano César Vallejo, primer novelista del realismo social. El argentino Jorge Luis Borges, el autor más representativo de la literatura fantástica, luego seguido por Bioy Casares y Julio Cortázar, el mejicano Carlos Fuentes y el guatemalteco Augusto Monterroso. El guatemalteco Miguel Angel Asturias, barroco y surrealista, nostálgico de las fábulas y los mitos indígenas. El chileno Pablo Neruda, maestro en poesía y en prosa, solidario con el dolor del mundo en sus temas recurrentes: la política, el amor y la justicia social. El mejicano Alejo Carpentier asimilador en su obra de la de los cronistas de Indias, las novelas de caballerías, la picaresca y los autores del 98. El venezolano Arturo Uslar Pietri, maestro de la novela histórica y de las crónicas periodísticas. El uruguayo Juan Carlos Onetti, existencialista en sus personajes desvalidos, sórdidos y tristes. El paraguayo Augusto Roa Bastos, novelador magistral de los misterios de la historia. El físico argentino Ernesto Sábato, narrador de soledades e incomunicaciones. El realismo mágico de Alejo Carpentier, Juan Rulfo y Rómulo Gallegos; la sorpresa imaginativa conductora del laberinto del relato en García Márquez, revolucionador del arte de contar; y el polirrealismo de Mario Vargas Llosa, asimilador de formas populares contemporáneas. El ensayo, como continuador del quehacer poético, novelístico y político, en el mejicano Octavio Paz.

Yo creo que toda esta maravillosa cosecha literaria hispanoamericana, sembrada hace diez siglos en la cuna de San Millán de la Cogolla, ha hecho cierto el deseo de Borges, al final de su ensayo "El lenguaje de Buenos Aires", cuando dice: "Nosotros quisiéramos un español dócil y venturoso que se llevara bien con la apasionada condición de nuestros ponientes y con la infinitud de dulzura de nuestros veranos y nuestras lluvias. Y con nuestra pública fer. Sucedió, además, que en estas idas y venidas del castellano, en este camino ya de vuelta de la lengua de nuestro siglo, la lírica, la novela, el teatro y el ensayo de esa especie de gradiente continuo de las épocas y las generaciones literarias de este lado español, se taracean con las del otro lado del océano para alumbrar en la literatura contemporánea hispanoamericana una de las más maravillosas creaciones culturales de la civilización. 